\title{
From Customer Orientation to Customer Satisfaction: The Gap Between Theory and Practice
}

\author{
Andy C. L. Yeung, T. C. Edwin Cheng, and Ling-Yau Chan
}

\begin{abstract}
The classical quality management theory suggests that different quality improvement practices have a similar positive effect on overall operational efficiency, leading to customer satisfaction. Based on a study of 225 organizations in the electronics industry in Hong Kong, we find that individual quality improvement practice has a specific effect on operational performance, rather than equally improving the overall operational efficiency. Our investigations indicate that customer orientation practices primarily affect time-based efficiency, while process improvement efforts help cost-related performance. On the other hand, emphasizing process-control systems leads to customer satisfaction directly without necessarily improving operations. While supporting the basic assertions of the classical quality management theory, these findings reveal that several problems exist in the practice of quality management in industry, and suggest that a re-direction of several quality management practices seems necessary. This research refines the understanding of quality management by explicating the specific effect of customer orientation and process management on organizational performance.
\end{abstract}

Index Terms-Customer orientation, customer satisfaction, operational efficiency, process improvement.

\section{INTRODUCTION}

Q UALITY management states that customer orientation and process management, embracing both the practice of continuous process improvement and the implementation of process-control systems, are vital to operational efficiency and customer satisfaction and, hence, to the success of an organization [29], [35], [38], [44], [59]. Customer orientation and process management are essential constructs in total quality management (TQM) [2], [14], [33], [36], and are closely linked to each other. For example, process management emphasizes knowledge of customers and market trends, which is acquired by interacting and cooperating with customers via business processes [67], [77]. In addition, effective process-control systems are based on a full understanding the requirements of customers [23], [58], [96]. Although the relationships between quality management and organizational performance have been investigated by a number of researchers [5], [40], [42], [78], little empirical work has been conducted with a focus on studying the impacts of customer orientation and process management on organizational performance.

Manuscript received August 15, 2001; revised March 15, 2003. Review of this manuscript was arranged by Department Editor J. K. Liker. This work is supported in part by the Hong Kong Polytechnic University under Grant G-YD19.

A. C. L. Yeung and T. C. E. Cheng are with the Department of Logistics, The Hong Kong Polytechnic University, Hung Hom, Hong Kong (e-mail: lgtandyy@inet.polyu.edu.hk).

L.-Y. Chan is with the Department of Industrial and Manufacturing Systems Engineering, University of Hong Kong, Kowloon, Hong Kong.

Digital Object Identifier 10.1109/TEM.2003.822466
Based on data from 225 electronics manufacturing organizations and using structural equation modeling (SEM) for data analysis, we examine the effects of customer orientation, continuous process improvement, and process-control systems on the operational performance of firms in a manufacturing environment. Using confirmatory factor analysis (CFA), we develop the relevant research constructs and measurement models for use in this study. Customer orientation refers to the extent to which the needs of customers are aware of, considered or addressed in different operations processes [3], [12], [33]. Continuous process improvement embraces efforts to reduce operational variations, mistakes and costs [35], [89]. Process-control systems refer to formal control procedures used in various stages of operations to ensure quality outcomes [15], [57], [61], including operational procedures adopted throughout the business processes to prevent potential problems and to ensure that quality requirements are met. Process-control systems involve developing, observing or inspecting procedures or performance, comparing them with some established standards, and then taking action if necessary. The objectives of these practices are 'holding the status quo' [61, p. 99].

The central idea of quality management is that quality improvement practices lead to operational efficiency and, subsequently, customer satisfaction. However, we hypothesize that different quality management practices might have different effects on operations. This is especially the case in a dynamic, fast-changing and competitive global market, in which every quality management practice may be purposely directed toward gaining a specific immediate result and targeted at attaining a particular operational performance outcome.

By comparing various structural models of the empirical data, we derive a framework representing these relationships. We then explore the implications of our research results for both academics and practitioners vis-à-vis prior findings in this area. The model developed here deviates markedly from the classical quality management theory in a number of aspects. Investigation into these differences highlights the existence of several problems in the practices of quality management currently being pursued in the Hong Kong electronics industry, the industry that provides the setting for this study.

This research conveys important messages to quality practitioners. The results indicate that improving operations is not about increasing control or merely adopting an orientation toward customers. Instead of orienting to some short-term and readily assessable targets, practitioners may need a right balance of various quality practices for long-term improvement. Currently, industrial buyers in the electronics industry emphasize process-control systems and standards, discouraging decisive 
improvement and breakthrough thinking. In redirecting their practices, educating suppliers as well as customers may be equally important. This study calls for the redirection of a number of current industrial practices in quality management and provides better insights into the constraints of quality management in actual practice.

\section{LITERATURE REVIEW}

\section{A. Focusing on Customers and Processes}

Although top management commitment, employee involvement, customer orientation, and process management are generally regarded as the pillars of quality management [12], [33], [35], [61], [66], [78], it appears that only customer orientation and process management have the most direct impact on operational efficiency and customer satisfaction [13], [61], [71], [77], [92]. Top management leadership and employee involvement are, in fact, drivers and supporting elements. This view is corroborated by a number of exploratory studies using the path analytic technique [5], [40], [95].

The literature on quality management suggests that customer orientation and process management, being key to achieving quality [12], [19], [76], have direct effects on time-based efficiency, cost effectiveness and customer satisfaction [33], [56]. Bergman and Klefsjo [12] explain that quality management can be divided into two dimensions: internal and external quality management. Internal quality management refers to appropriate processes or operations management, while external quality management involves addressing customer needs and fulfilling customer requirements. They maintain that pursuing both internal and external quality management will lead to fewer complaints, lower costs and speedy operations.

Similarly, Reed et al. [76] assert that customer orientation and operations orientation are key to organizational performance. They propose a framework illustrating these relationships (as presented in Fig. 1), suggesting that both customer and operations orientations have similar ultimate effects on operational performance. However, Reed et al. [76] warn that a customer orientation and an operations orientation should not be confined only to addressing external and internal issues, respectively. Instead, a customer orientation helps the firm to deal with both external and internal issues such as product-design efficiencies, as does an operations orientation such as customer requirements for product reliability.

Although researchers generally believe that customer orientation and process management have exclusive effects on various aspects of organizational performance, some empirical studies exploring these relationships have not reached consistent results. Flynn et al.'s [40] study of 42 manufacturing companies in the U.S. found that customer relationships are not related to the competitive performance of a firm. Based on data from the same database, Anderson et al.'s [5] study suggested that continuous improvement is not related to customer satisfaction, and contradicted Deming's [34], [35] quality management ideas [4]. Forza and Filippini [42] developed a quality management model to investigate the relationships among customer orientation, process control, customer satisfaction and quality conformance. They found that process control, although leading to

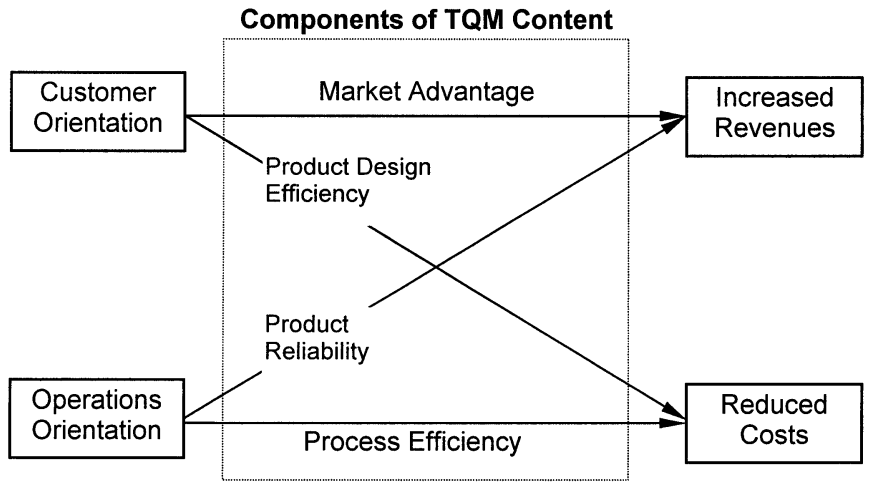

Fig. 1. Quality management orientation and performance [71, p. 33].

greater process conformance, does not increase customer satisfaction. They called for further investigation into these issues.

\section{B. Development of Hypotheses}

The present research aims at providing additional insights by investigating specifically the relationships with a larger sample size from a single industry. We first develop a model rooted in the literature and propose five alternative models from different perspectives.

In the highly competitive and changing electronics industry, speedy and timely operations are always an extremely important concern to customers. Hence, customer orientation, such as analyzing customer concerns and responses proactively, should lead to time-based efficiency. On the other hand, the impacts of continuous process improvement, such as constant efforts to reduce deviations and defects, on organizational performance should be rather comprehensive [15], [61]. Taguchi et al. [89] suggested that performance begins to gradually deteriorate as the design parameter deviates from its target or optimum value. He, therefore, proposes that the loss of quality costs should be measured by the deviation from the ideal value [8], [36], [48], [87], [88]. Continuous efforts in optimizing processes and reducing variations will decrease operational costs [4], [79]. Deming points out that the central problem in process management is the failure to understand the source of information variation. He asserts that "removal of common causes of trouble and of variation, of errors, of mistakes, of low production, of low sales is the responsibility of management" [35, pp. 321-322]. While reducing mistakes and variations in operations and lowering costs [12], [35], [60], continuous process improvement also addresses the issues regarding process effectiveness, capability, and cycle time. As a result, continuous process improvement leads to time-based efficiency [35], [60], [76]. Likewise, process-control systems, such as following established operational procedures and work instructions, are essential and have a wide impact on operational performance. Process-control systems prevent potential operational problems and help to ensure that customer requirements will be met consistently, thereby reducing waste and operational costs [73], [32]. Well-defined process-control systems ensure that the most effective operational procedures are adopted [15], [32] and prevent operational mistakes from occurring, resulting in time-based efficiency [61]. Business process-control systems are emphasized and developed throughout business processes to gain the goodwill of customers and boost their confidence [16], 


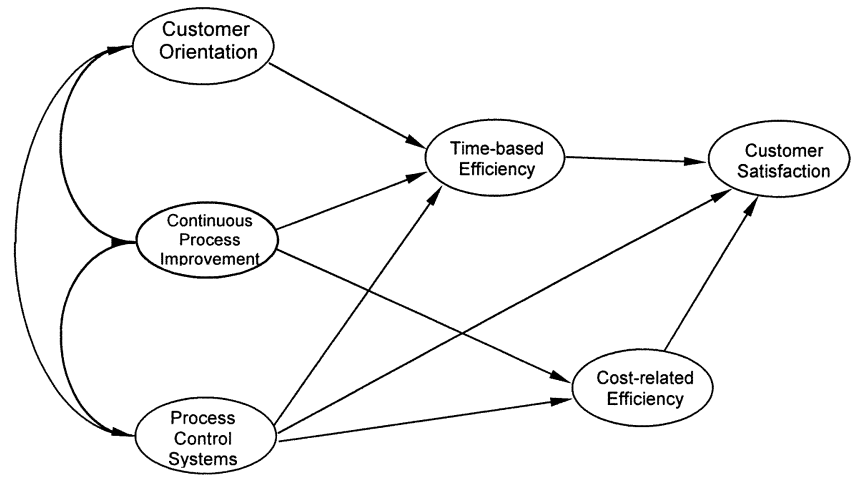

(a)

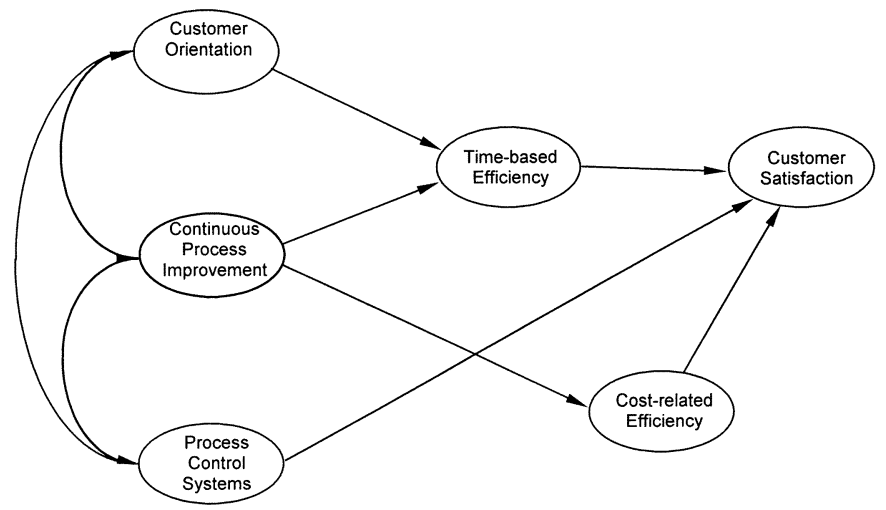

(c)

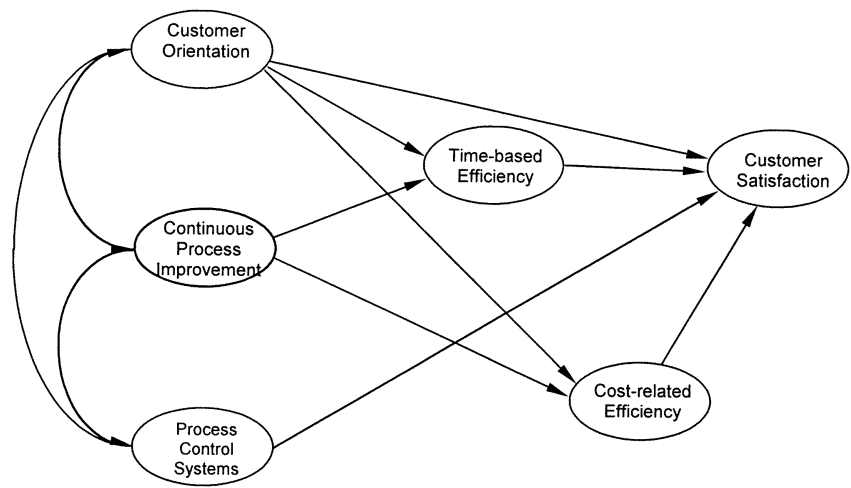

(b)

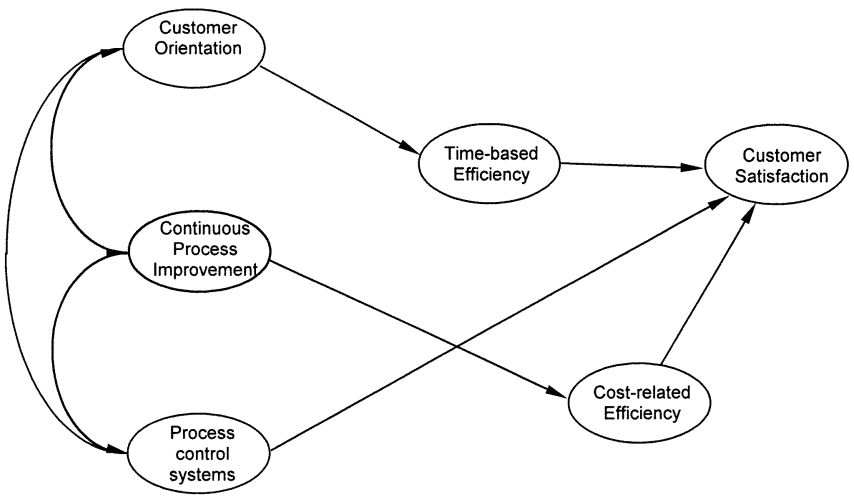

(d)

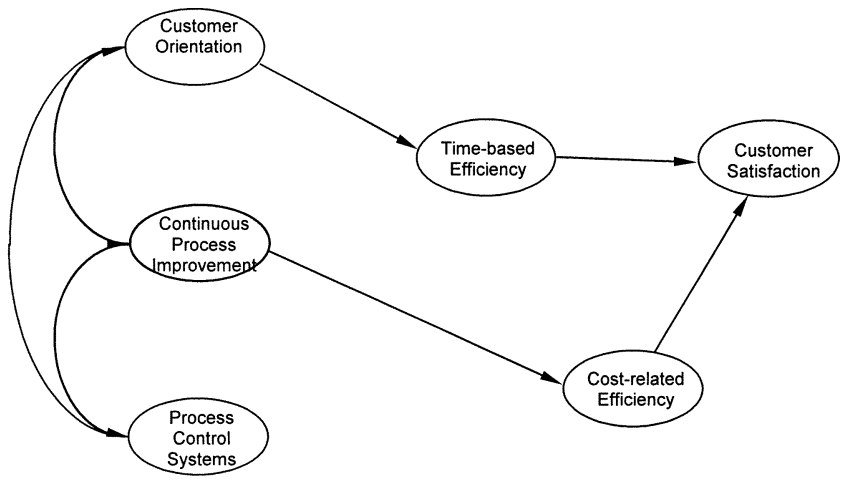

(e)

Fig. 2. (a) Structural model A. (b) Structural model B. (c) Structural model C. (d) Structural model D. (e) Structural model E.

[47], leading to their satisfaction directly. Model A is developed to postulate these speculations.

1) Structural Model A [Fig. 2(a)]:

H1a) Customer orientation leads to time-based efficiency.

H1b) Continuous process improvement leads to both timebased and cost-related efficiency.

H1c) Process-control systems not only ensure time-based and cost-related efficiency but also lead to customer satisfaction directly.

In dynamic industrial markets, products are developed to fulfill anticipated demands or to meet specific needs [12], [77]. Apart from leading to time-based efficiency, customer orientation is centered at doing the right thing, reducing engineering changes, and decreasing quality costs. Customer orientation may also improve customer relationships directly through mutual communication and understanding [74], [77], [85]. On the other hand, process management and improvement, instead of process control, has been increasingly emphasized by some quality experts [35], [89]. Some state that process-control systems simply ensure the conformance of a product to specifications [37], instead of improving operations. As a result, process-control systems may not have a direct effect on time-based or cost-related efficiency. Model B is hypothesized accordingly.

Structural Model B [Fig. 2(b)]:

$\mathrm{H} 2 \mathrm{a})$ Customer orientation not only leads to both time-based and cost-related efficiency, but also leads to customer satisfaction directly.

H2b) Continuous process improvement leads to both timebased and cost-related efficiency. 
H2c) Process-control systems do not improve time-based or cost-related efficiency. However, they lead to customer satisfaction directly.

Developed upon previous models, we further postulate that customer orientation and process-control systems have a rather specific effect on organizational performance, leading mainly to time-based efficiency and customer satisfaction, respectively. This is because a certain quality management construct may be typified in some standard practices, developed narrowly to achieve a certain operation objective or oriented to a certain customer requirement. However, continuous process improvement may have a relatively comprehensive effect, leading to both time-based and cost-related efficiency. Model $\mathrm{C}$ is developed as follows.

\section{Structural Model C [Fig. 2(c)]:}

H3a) Customer orientation leads to time-based efficiency only.

H3b) Continuous process improvement leads to both timebased and cost-related efficiency.

H3c) Process-control systems do not improve time-based or cost-related efficiency. However, they lead to customer satisfaction directly.

Based on Model C, we further hypothesize that each of these three quality management constructs has a specific effect on organizational performance. While customer orientation leads to time-based efficiency and process-control systems enhance customer satisfaction directly without improving operational efficiency, continuous process improvement only enhances cost-related efficiency. Thus, we have model D.

Structural Model D [Fig. 2(d)]:

$\mathrm{H} 4 \mathrm{a})$ Customer orientation leads to time-based efficiency only.

H4b) Continuous process improvement leads to cost-related efficiency only.

H4c) Process-control systems do not improve time-based or cost-related efficiency. However, they lead to customer satisfaction directly.

If process-control systems do not improve operational efficiency, then it is reasonable to suspect that process-control systems are not properly developed according to customer requirements and, thus, will not lead to direct customer satisfaction at all. We then further propose a more nested model based on Model D. That is, while customer orientation and continuous process improvement lead to time-based and cost-related efficiency, respectively, process-control systems have no effect on any organizational performance constructs. Thus, we formulate Model E.

Structural Model E [Fig. 2(e)]:

H5a) Customer orientation leads to time-based efficiency only.

H5b) Continuous process improvement leads to cost-related efficiency only.

H5c) Process-control systems do not improve time-based efficiency, cost-related efficiency, or customer satisfaction.

\section{ReSEARCh Design AND ANAlysis Methodology}

\section{A. Research Design}

The Hong Kong electronics industry provides an appropriate operating environment to conduct this study. The world's electronics industry is competitive, fast-changing and technology-based [10], [24], [26], [27], [75], [94]. Hong Kong's electronics industry is highly export-oriented and, hence, operates in an extremely competitive environment in a free global market. In the face of strong competition from other regions, the local electronics industry must enhance its productivity, improve the quality of products and services, and lower costs. In order to take advantage of cheap labor and an abundant supply of land, most electronics manufacturers in Hong Kong have relocated their production to the Pearl River Delta (PRD) region in Guangdong Province, China. Benefiting from the rapid economic development of the PRD region, the electronics industry attracted a large amount of foreign investment and underwent up-scaling rapidly in the 1990s. Among these companies, a large number of them are original equipment manufacturers (OEM) or original design manufacturers (ODM) with major customers (or for their parent companies) in the U.S., Japan, and European countries.

Electronics manufacturing is one of the major industries in this region. According to research on the Hong Kong electronics industry [53], the total output of Hong Kong electronics manufacturers in Hong Kong and the PRD region is around 42 billion U.S. dollars annually. The total export output is about 28 billion U.S. dollars. The U.S., Japan, and Singapore are Hong Kong's largest export markets for electronics products, accounting for $26.5 \%, 7.1 \%$, and $6.8 \%$ of the total exports, respectively. In recent years, the industry has been moving toward the manufacture of more sophisticated and technology intensive products [54]. According to the latest census report, there are about 1000 electronics manufacturing firms in Hong Kong. Among these companies, most of them are small- and medium-sized firms. Only organizations with 50 or more employees were considered in this study.

This research proceeded in three phases. First, we conducted a pilot study of six organizations to pretest the questionnaire. We originally selected three or four indicators for each construct (see Table II) based on literature review and empirical research in this area [2], [39]. We then discussed the choice of indicators with the practitioners, initially mainly operations and quality managers. We revised the indicators to suit the nature of the electronics industry or to a local context if necessary. For instance, "product returns due to bad quality" was considered an indicator of customer satisfaction. However, this practice is not common in the electronics industry, especially for overseas orders. This indicator was dropped. Three indicators for each construct were chosen based on the literature and inputs from the practitioners. In order to make sure that these questions were interpreted according to our original design and that they conveyed a precise meaning to the respondents, we interviewed some respondents of the questionnaire at this stage. We studied how they had interpreted the questions and determined their answers. Our interviews with 19 respondents in six organizations confirmed that 
TABLE I

POSITIONS OF THE ADMINISTRATORS

\begin{tabular}{lrr}
\hline \multicolumn{1}{c}{ Positions } & Frequency & Percentage \\
\hline Top Management (e.g., Managing Director) & 79 & $35.1 \%$ \\
Senior Technical Managers (e.g., Operations Manager) & 59 & $26.2 \%$ \\
Senior Non-technical Managers (e.g., Marketing Manager) & 52 & $23.1 \%$ \\
Other Managers (e.g., Production \& Material Control Manager) & 22 & $9.8 \%$ \\
Chief/Senior Engineers (e.g., Chief Manufacturing Engineer) & 13 & $5.8 \%$ \\
Total & $\mathbf{2 2 5}$ & $\mathbf{1 0 0 \%}$ \\
\hline
\end{tabular}

the indicators generally conveyed a precise meaning as we had proposed.

During the second phase, we randomly selected about 330 companies from an electronics directory to contact for possible participation in the survey. We managed to contact a total of 302 electronics firms. Among them, 246 companies were successfully invited to join this research. However, 21 firms dropped out from the study due to various reasons such as complexity of the questionnaire or confidentiality of the information sought. A total of 225 useful questionnaires were eventually returned, yielding a response rate of $74.5 \%$ of the total number of companies successfully contacted. Companies agreeing to participate in the present study were invited to appoint an administrator, who was normally a senior staff member of the firm, such as the General Manager or a Director, to administrate the survey questionnaire and serve as a contact point for the researchers. The administrators also helped the researchers by arranging a series of in-depth interviews, which were conducted in the third phase of this study. Table I presents the profiles of the administrators. The project was beneficial to the participating organizations as they were provided with a detailed analysis of their quality management systems (QMS).

In this research, we collected one survey questionnaire from each company. However, we instructed the administrators clearly that different sections of the questionnaire must be filled by the relevant personnel in a management position. The indicators of a construct were sometimes filled by a few departments. For example, "customer orientation" involved design, production, and marketing personnel, while continuous process improvements concerned mainly production and quality departments. Although organizational structures varied greatly among the surveyed companies, at least three departments (production, quality, and marketing) of each company were involved in this survey.

A total of 16 companies were contacted for in-depth interviews in the third stage in late 1999. Since the organizations selected only made up about $7 \%$ of the total number of companies surveyed, we applied stratified sampling to select the subjects. Based on another set of empirical data from the electronics industry and by using cluster analysis [95], a taxonomy of QMS was developed. The taxonomy classifies organizations into four types - undeveloped, framed, accommodating, and strategic quality systems-in accordance with the level of advancement of their quality management practices. Four companies from each type were selected, which ensured that organizations with different levels of quality management practices were interviewed. Seven of them were foreign owned companies, including the U.S., Japan, and The Netherlands. The interviews were conducted in either their factories in Hong Kong or the PRD region.

There were two major objectives for these qualitative investigations. First, we tried to verify the quantitative data reported in the questionnaire. We selected two to three departments in each firm and carefully audited their responses to the questionnaire by cross-checking organizational records and examining actual figures. We paid special attention to the answers of some behavioral questions, verifying if they actually reflected daily operational practices. Our triangulation effort with these companies suggested that the accuracy of the data reported was not a concern. Second, we sought qualitative explanations for the quantitative data collected from the survey questionnaires. By interviewing quality and operations professionals, we explored their understanding of the surveyed ideas such as customer orientation, and how their interpretations in turn affected their daily operations. We also attempted to interview staff at different levels in the organizations, including operators, workers, and members of quality-control circles, if available. We spent a full day at each plant we visited and reviewed some quality system documents for verification purposes.

\section{B. Structural Equation Modeling}

Structural equation modeling (SEM) is a well-developed data analysis method, incorporating many traditional data analysis techniques as special cases [70]. SEM allows researchers to frame increasingly precise questions about the phenomena in which they are interested [63]. Hughes et al. [55] stated that SEM provides researchers with a method for both estimating structural relationships among unobservable constructs and assessing the adequacy with which those constructs have been measured. They further point out that the use of SEM entails a mode of thinking [50] about theory construction, measurement problems, and data analysis that is helpful in building and testing the theory more precisely. However, the effective use of SEM is subject to understanding of its limitations. First, SEM requires a precise and relatively narrow definition of research constructs. Operationalizing a construct by using too many indicators often results in a misfit in measurement models [46]. Second, SEM cannot be used in exploratory research [50], [63]. It is essentially a confirmatory technique requiring a researcher to develop 
TABLE II

SELECTED INDICATORS FOR THE RESEARCH CONSTRUCTS

\begin{tabular}{|c|c|}
\hline Construct & Indicators (Likert Scale 1-7) \\
\hline \multirow[t]{3}{*}{ Customer Orientation } & $\begin{array}{l}\text { 1. Our product and process design engineers are always clear about the } \\
\text { customer requirements and market trends. }\end{array}$ \\
\hline & $\begin{array}{l}\text { 2. Our production department regularly reviews and analyzes customer } \\
\text { satisfaction surveys to seek opportunities for improving product quality. }\end{array}$ \\
\hline & $\begin{array}{l}\text { 3. Our marketing staff are fully aware of and responsible for the quality of the } \\
\text { products and services they provide to customers. }\end{array}$ \\
\hline \multirow[t]{3}{*}{$\begin{array}{l}\text { Continuous Process } \\
\text { Improvement }\end{array}$} & $\begin{array}{l}\text { We are not satisfied with just meeting the required specifications in our } \\
\text { production processes, efforts are always made to minimize deviations from } \\
\text { the target points. }\end{array}$ \\
\hline & $\begin{array}{l}\text { 2. No matter how low the defect rate is, we always strive to decrease it } \\
\text { continuously. }\end{array}$ \\
\hline & $\begin{array}{l}\text { 3. We regularly try to find out the causes for high operational costs, } \\
\text { identifying and solving them to reduce the unit cost of manufacturing. }\end{array}$ \\
\hline \multirow[t]{3}{*}{ Process Control Systems } & $\begin{array}{l}\text { 1. We regularly review every contract to make sure that we fully understand } \\
\text { the requirements and are capable of meeting all the requirements before } \\
\text { accepting it. }\end{array}$ \\
\hline & $\begin{array}{l}\text { 2. Product or service specifications and operational instructions are always } \\
\text { documented clearly. }\end{array}$ \\
\hline & $\begin{array}{l}\text { 3. There are clear systems and procedures to make sure that no products are } \\
\text { released until the required inspections and tests are completed. }\end{array}$ \\
\hline \multirow{3}{*}{$\begin{array}{l}\text { Time-based Operational } \\
\text { Performance }\end{array}$} & 1. Delivery Speed and Reliability (Timeliness of Delivery) \\
\hline & 2. Manufacturing Lead Time (Production Cycle Time) \\
\hline & 3. Inventory Turnover Rate \\
\hline \multirow{3}{*}{$\begin{array}{l}\text { Cost-related Operational } \\
\text { Performance }\end{array}$} & 1. Total Quality Costs (relative to total output) \\
\hline & 2. Engineering changes rates in the production stage \\
\hline & 3. *Unit Cost of Manufacturing \\
\hline \multirow[t]{3}{*}{ Customer Satisfaction } & 1. Product Reliability \\
\hline & 2. Customer Complaints \\
\hline & 3. Customer Relations \\
\hline
\end{tabular}

* excluded from the analysis

a few competing models for hypothesis testing. As pointed out by Hair et al. [49] and demonstrated by other researchers [69], [82], applying SEM in an exploratory manner is invalid. Furthermore, SEM is only suitable for small and medium structural models with few constructs. Using SEM in testing complex models will always lead to the rejection of the models regardless of their validity [9], [11].

\section{INSTRUMENT DEVELOPMENT}

The idea of SEM is based on the observations that every theory implies a set of covariance or correlation existing in the observed data and, if the theory is valid, it explains and reproduces the patterns of covariance found in the empirical data [63]. A structural equation model consists of two parts: the measurement model and the structural model, which should be tested separately [3], [17], [49]. This is because a meaningful structural model cannot be established unless valid and reliable measurement models are assured. A measurement model is a submodel in SEM [49]. Generally, each construct in a measurement model requires only two or three indicators [50], since the sampling error increases with the number of manifest variables [45].

\section{A. Selection of Indicators}

Customer orientation assures a correct effort of process management [67], [76]. Customer orientation implies understanding what the customers want and need, at present and in the future [12]. Dean and Bowen [33] point out that practices exemplifying customer orientation include promoting direct contact with customers, collecting information about customers' expectations, and disseminating this information within the organization. In recent years, customer orientation is stressed across different stages of business processes [67], [71], [76]. As a result, manifest variables were selected to represent customer orientation across different stages of operations, including product design, production, and marketing and services [12], [33], [43], [67], [74]. 
TABLE III

GOODNESS OF Fit INDICES FOR MEASUREMENT MODELS OF ENDOGENOUS CONSTRUCTS

\begin{tabular}{|c|c|c|c|c|c|}
\hline Goodness of fit Measures & Criteria & Model 1 & Model 2 & Model 3 & Model 4 \\
\hline Paired Constructs & - & $\begin{array}{r}\text { Customer orientation } \\
\text { and Continuous } \\
\text { Process Improvement }\end{array}$ & $\begin{array}{r}\text { Continuous Process } \\
\text { Improvement and } \\
\text { Process Control } \\
\text { Systems } \\
\end{array}$ & $\begin{array}{r}\text { Time-based } \\
\text { Operational Efficiency } \\
\text { and Cost-related } \\
\text { Operational Efficiency }\end{array}$ & $\begin{array}{r}\text { Cost-related } \\
\text { Operational Efficiency } \\
\text { and Customer } \\
\text { Satisfaction }\end{array}$ \\
\hline Sample moments & - & 21 & 21 & 15 & 15 \\
\hline Distinct Parameters & - & 13 & 13 & 11 & 11 \\
\hline $\begin{array}{l}\text { Chi-square }\left(\chi^{2}\right) \\
\text { Absolute Fit Index }\end{array}$ & - & 13.362 & 11.167 & 4.875 & 3.993 \\
\hline Probability of $\chi^{2}$ & $\mathrm{p} \geq .05$ & 0.100 & 0.192 & $p=.300$ & $p=.407$ \\
\hline Chi-square/Degrees of Freedom $\left(\chi^{2} / d f\right)$ & $\leq 3.0$ & $1.670(d f=8)$ & $1.396(d f=8)$ & $1.219(d f=4)$ & $.998(d f=4)$ \\
\hline Goodness of fit Index (GFI) & $\geq .90$ & .980 & .984 & .992 & .993 \\
\hline Root Mean Square Residual (RMSR) & $\leq .10$ & .055 & .045 & .036 & .030 \\
\hline Comparative Fit Index & & & & & \\
\hline Normed Fit Index (NFI) & $\geq .90$ & .971 & .983 & .972 & .982 \\
\hline Non-Normed Fit Index (NNFI) & $\geq .90$ & .978 & .991 & .987 & 1.000 \\
\hline Comparative Fit Index (CFI) & $\geq .90$ & .988 & .995 & .995 & 1.000 \\
\hline
\end{tabular}

Process management is a broadly defined construct that comprises a wide range of operational practices, concerning both process-control systems and continuous process improvement [59], [61], [76]. Continuous improvement in operations requires a continuous effort in decreasing variations [4], [35] and operational mistakes. Three indicators were chosen to reflect continuous process improvement efforts. They represent a continuous effort in reducing process deviations or variations, process defects, and process operational costs [35], [48], [87]. Another three procedures or practices were selected to represent process-control systems. Three variables were adopted to represent the system procedures in three important stages of process control, which included controlling process inputs by regulating orders and contracts, controlling process operations, and controlling process output [15], [57], [61]. Table II presents a summary of the indicators for all research constructs under study as the same wording in the survey. A Likert scale of one to seven was used for all indicators. Respondents were asked to rate these quality management practices and changes of operational performance in the past three years.

Similarly, dependent variables were selected and measurement models were developed for endogenous variables. Delivery speed and reliability, manufacturing lead time, and inventory turnover rate were selected as indicators [5], [36], [40], [95] for time-based operational efficiency. Cost-related efficiency is related to costs of quality and engineering changes in this study [31], [35], [36]. Deming [35], [36] warns that engineering changes are costly and sometimes impossible. Three indicators, including total quality costs, engineering changes [35] in the production stage, and the unit cost of manufacturing, were originally selected [12], [38], [36], [61] to represent cost-related operational efficiency. However, the results of CFA suggested that the unit cost of manufacturing was an insufficient indication of cost-related efficiency. This may be due to the fact that the unit cost of manufacturing is largely influenced by the operational environment such as incoming material or rental costs, apart from operational efficiency. As a result, only the first two indicators were used. Finally, product reliability [44], [64], [76], customer complaints, and customer relations were selected [5], [12], [36], [40] to indicate the latent construct of customer satisfaction.
In this study, customer orientation, continuous process improvement, and process-control systems are exogenous latent constructs. However, these three constructs cannot be verified by CFA individually. This is because a single measurement model consisting of a single construct with three indicators has a negative degree of freedom. That is, the number of distinct sample moments is less than the number of distinct parameters to be estimated, resulting in an under-identified model. Instead, these latent constructs are tested in pairs. For example, customer orientation and continuous process improvement form a measurement model as Model 1 (see Table III).

\section{B. Goodness of Fit Measures}

Four measurement models were established and tested by Analysis of Moment Structures (AMOS), a computer software for SEM [6]. The recommended criteria for fit measures [2], [20], [22], [63] and the results of the analysis of measurement models are shown in Table III. The chi-square statistics of these models are insignificant, while the GFI values are well above 0.9 and the root-mean square residual (RMSR) values are below 0.1 , suggesting a good fit between the implied covariance in the model and the observed covariance from the data. Comparative fit indices are also well above the general criteria, providing evidence against the hypothesis of being a null model. All these measures suggest that the measurement models have a satisfactory model fit.

\section{Convergent and Discriminant Validity}

Convergent validity relates to the degree to which different measures of the same construct are highly correlated and hence yield the same result [25], [52]. Discriminant validity is the degree to which measures of different latent constructs are unique [72] enough to be distinguished from another construct. Generally, a construct with a reliability value of at least 0.50 and a significant $t$-value for loadings, say $t>2.0$, is considered to be convergently valid [20]. Ranging from 0.553 to 0.873 , all reliability values, represented by $\lambda$ 's, are higher than 0.5 and the $t$-values for loadings ( $\lambda^{\prime}$ s) are greater than 2.0, implying that the 
TABLE IV

GOODNESS OF Fit INDICES OF COMPLETING STRUCTURAL MODELS

\begin{tabular}{lrrrrrr}
\hline Goodness of Fit Measures & Criteria & Model A & Model B & Model C & Model D & Model E \\
\hline Absolute Fit Measures & & & & & & \\
Chi-square $\left(\chi^{2}\right)$ of estimated model & & 122.043 & 122.599 & 123.412 & 124.701 & 167.491 \\
Degrees of Freedom & & 108 & 108 & 110 & 111 & 112 \\
Significant Level of Chi-Square & $\mathrm{p} \geq .05$ & .168 & .159 & .180 & .177 & .001 \\
Chi-square/ Degree of Freedom $\left(\chi^{2} / \mathrm{df}\right)$ & $\leq 3.0$ & 1.130 & 1.135 & 1.122 & 1.123 & 1.495 \\
Goodness of fit Index (GFI) & $\geq .90$ & .941 & .941 & .941 & .940 & .925 \\
Root Mean Square Residual (RMSR) & $\leq .10$ & .061 & .060 & .061 & .063 & .168 \\
Comparative Fit Measures & & & & & & \\
Chi-square of Null or Independent Model: & & 1534.607 & 1534.607 & 1534.607 & 1534.607 & 1534.607 \\
Normed Fit Index (NFI) & $\geq .90$ & .920 & .920 & .920 & .919 & .891 \\
Non-Normed Fit Index (NNFI) & $\geq .90$ & .987 & .987 & .988 & .988 & .952 \\
Comparative Fit Index (CFI) & $\geq .90$ & .990 & .990 & .990 & .990 & .960 \\
Adjusted goodness of fit index (AGFI) & $\geq .90$ & .916 & .916 & .917 & .918 & .898 \\
Parsimonious Fit Measures & & & & & .7317 & .750 \\
Parsimony Normed Fit Index (PNFI) & - & .731 & .731 & .744 & .750 \\
Parsimony Goodness of Fit Index (PGFI) & - & .664 & .664 & .676 & .682 & .677 \\
\hline
\end{tabular}

relationships between the indicators and constructs are statistically significant. Convergent validity is also reflected by comparative fit index (CFI) and normed fit index (NFI) values of 0.9 or above [2]. Discriminant validity can be judged by fixing the correlation between various constructs to 1.0 , then re-estimating the fixed model. A significant difference of the chi-square statistics between the fixed and unconstrained models indicates high discriminant validity [20], [41]. By fixing the correlation ( $\phi$ 's) between the constructs in Model 1-Model 4 to the perfect correlation of 1 , the chi-square values increased by $16.316,16.412$, 48.073 , and 37.183 , respectively. With changes in one degree of freedom, these values were significant at $p=0.01$ level $\left(\chi^{2}>6.635\right)$.

\section{Model Development AND Analysis}

\section{A. Model Development Strategy}

It is suggested [9], [30] that SEM is best conducted in the form of comparisons among different plausible models that are nested in one another and can be justified theoretically [9]. If modifications are carried out in an exploratory or "try and error" manner, the final model is sometimes incorrect, in the sense that it has a good model fit but is invalid in representing a "true theory" [9], [21]. In SEM, several models can be found to have an acceptable fit, and the objective of the researcher is to find the most nested one with a good fit. Nested models have the same constructs of a general model, but with fewer estimated relations [49], [80]. Bentler and Chou [11] point out that in an ideal situation, a researcher builds a series of submodels that shed light on the key features of a general model and these models are compared. If the goodness of fit measures of the more restricted model is comparable to that of the more general models, the restrictions are accepted. A simpler model is chosen, as it better represents the theory.

\section{B. Developing Competing Models}

Five competing models, Models A-E as presented in Fig. 2(a)-(e), respectively, were proposed and tested according to the suggestions in Section II.B. Model A is a general model that hypothesizes customer orientation has no direct effects on both customer satisfaction and cost-related efficiency. Model B is an alternative of Model A. Model C is a nested model of Models A and B that the constraints of both Model A and Model B are imposed. Model D, a nested model of Model C, further hypothesizes that continuous process improvement has no direct effects on time-based efficiency. Model E, which further simplifies Model D to become the most parsimonious model, proposes that process-control systems have no effects on customer satisfaction.

\section{Analysis of Competing Models}

The analysis of structural models yields a number of goodness of fit indexes as shown in Table IV. Models A-D are good fit models as they meet the general criteria of both absolute fit measures and comparative fit measures in SEM analysis. The $\chi^{2}$ values are insignificant, implying no evidence of misfit. The RMSR values are well below 0.1, indicating a low discrepancy between the implied covariance in the model and observed covariance in the data. Model E, however, is a poor fit model, as evidenced by a significant chi-square statistic, a high RMSR value, a marginal value of adjusted goodness of fit index (AGFI), and a significant increase of the $\chi^{2}$ value. This model is rejected even though it is the most parsimonious model.

Although Models A-D all have acceptable goodness of fit indexes, Model D is chosen as it represents the most parsimonious good-fit model. The figures in Table IV suggest that although model $\mathrm{D}$ is a more restricted model as compared to model C, the $\chi^{2}$ statistic increases only very slightly (change in $\chi^{2}=124.701-123.413=1.288$ ). With a change in one degree of freedom, the $\chi^{2}$ statistic is significant at 0.01 level only if the $\chi^{2}$ statistic increases by 6.635 or more. A more parsimonious model is always preferred if the $\chi^{2}$ statistic does not increase significantly with the increase in the degrees of freedom. Model D has a good absolute fit and comparative fit, which are as good as those of Models A-C, but with Parsimony normed fit index (PNFI) and Parsimony goodness of fit index (PGFI) values superior to these models. Additionally, unlike Models A-C, all parameters (paths) in Model D are significant as the $t$-values 


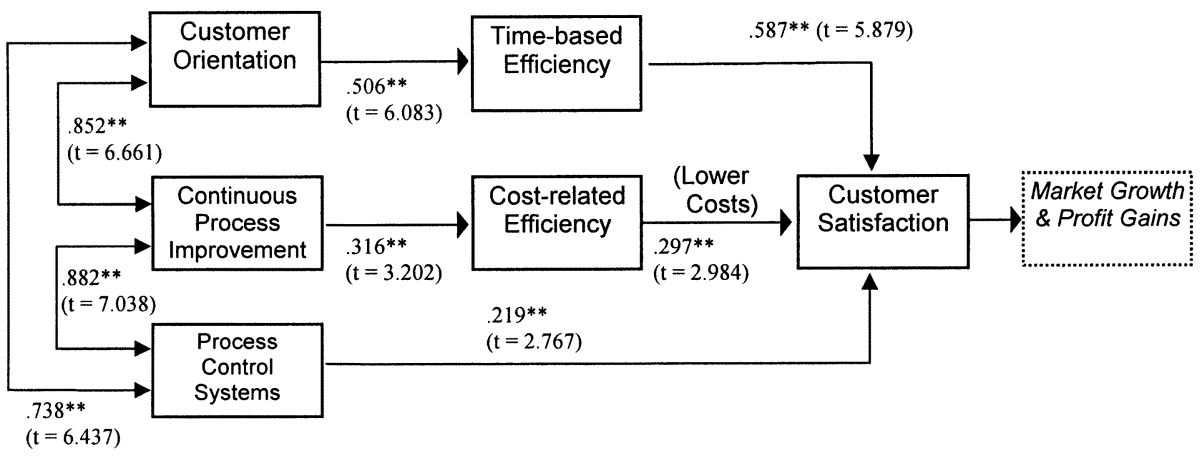

Fig. 3. Relationships among constructs in the final model.

are greater than 2.0 (see Fig. 3). All these indexes suggest that Model D is a good representation of the "true model."

\section{Interpretations of the Final Model}

The relationships among the various constructs with standardized regression weights and $t$-values in the final model are displayed in Fig. 3. The results show that customer orientation, continuous process improvement, and process-control systems are highly interrelated. This may be due to the fact that they are influenced strongly by the same underlying factors, which were not investigated in the present analysis. Customer orientation is highly associated with time-based efficiency, which, in turn, affects customer satisfaction. Continuous process improvement has a direct impact on cost-related performance only. The hypothesis that continuous process improvement is not associated with time-based efficiency and customer satisfaction is supported. The postulation that process-control systems have no effects on operational efficiency but make customer satisfied directly is also supported in the model.

\section{DISCUSSION}

\section{A. Customer Orientation and Operational Performance}

The statistical results suggest that, with customer orientation and awareness of customer needs at different stages of the business operations, organizations can actually provide more flexible (reduced lead time) and timely services (timely and reliable deliveries), which could lead to satisfied customers (fewer complaints, reliable products, and improved relations). However, customer orientation does not seem to improve cost-related efficiency. A total of 31 senior executives in 16 organizations were interviewed during the last phase of this study. Many of them suggested that customer orientation practices often led to extra costs in fulfilling customer expectations. Customer orientated organizations generally focus on production schedules and delivery times and reliability. Customer orientation is often achieved through a unilateral effort. For instance, when asked about how to enhance customer cooperation and sustain customer satisfaction, most executives spoke of improving facilities, speeding up deliveries, and reducing defects and nonconformance during customer audits. Very few executives in these 16 organizations mentioned the use of more advanced methods such as joint product development or improving product design, which require a closer cooperation with customers. It seems that the primary concern of operations managers is to satisfy customers by providing the required products according to the agreed schedules. Although customers were also concerned about cost effectiveness in their supplier company, these data, as well as the criteria for assessing these data, were not readily available.

By focusing on customers, extra operational expenses or costs of quality may be incurred as a result of adopting formal systems, documents, and records. To prevent engineering changes and reduce the costs of quality, customer cooperation plays a key role. Deming advises that "the customer's ultimate aim is continual improvement of quality along with lower costs" [36, p. 229], implying that customer orientation should also be applied to cost-efficient processes, not only to timely operations and formal systems. Since many suppliers are not cooperating with their customers in reducing operational variations, mistakes and costs, the association between customer orientation and cost-related efficiency is insignificant.

Consistent with that of a recent study by Ahire and Dreyfus [1], our model seems to indicate that customer orientation is not directly related to customer satisfaction. We believe that customers are satisfied only when their requirements and expectations are fulfilled in a timely manner at reasonable prices [7], [36]. As found in this study, customer satisfaction is influenced directly by the operational efficiency and process-control systems of their suppliers.

\section{B. Continuous Process Improvement and Operational Performance}

Our data seem to indicate that continuous process improvement is significantly related to cost-related efficiency as suggested by quality experts such as Deming [35] and Taguchi et al. [89]. This study provides important empirical support for this assertion. The results indicate that continuous process improvement, instead of process-control systems, significantly drives down costs. A possible explanation for this is derived from classical quality management theory. Deming [35] suggests that most of the operations costs are common causes, which make up about $94 \%$ of total operational costs, while special costs only account for 6\%. Common causes are incapable operations that are inherent in business systems and occur regularly, such as poor processes or incompetent operators. Special causes are due to some unexpected mistakes or accidents that occur in operations, such as the use of wrong parts or process breakdowns. Similarly, 


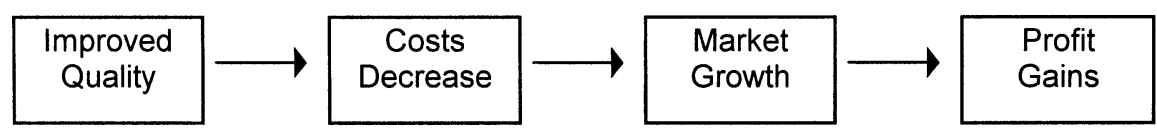

Fig. 4. Deming reaction chain.

Juran and Gryna [61] suggest that the costs of poor quality are due to chronic (common) and sporadic (special) quality problems, which make up more than $85 \%$ and $15 \%$ of the costs, respectively. Juran [60] points out that quality control includes putting out a fire and monitoring sporadic problems. The function of process-control systems is to prevent, detect, and solve problems due to special causes [59], [61]; they cannot solve operational problems due to common causes. For instance, a manufacturing process producing $0.5 \%$ defective parts may be regarded as a "nature occurrence" and a capable process. This is not considered as a process mistake and, thus, cannot be prevented by process-control systems or procedures. It is likely that continuous process improvement reduces the level of chronic problems or common causes that lead to high operational costs and presents a huge opportunity for cost reduction. Process-control systems, on the other hand, may be used for preventing the special or sporadic causes and, thus, are not significantly related to cost savings.

\section{Process-Control Systems and Operational Performance}

Our findings seem to suggest that process-control systems are closely related to customer satisfaction, but not to time-based efficiency or cost-related efficiency. Choi and Eboch [23] surveyed 339 manufacturing firms in the U.S. and suggested that TQM practices are highly correlated with customer satisfaction but not with plant performance. They explained that manufacturing plants are as much an entity of performance that seeks quality and efficiency as an entity of institutionalization and political dynamics that seeks legitimacy and goodwill of the customers. It seems that institutional forces drive organizational systems or activities by social factors such as external conformity pressures from regulatory bodies or customers, rather than economic or efficiency factors [18], [93], and, thus, do not necessarily improve cost-related efficiency.

The findings here reveal that it is process-control systems that lead to customer satisfaction directly. From our interviews, we learned that operations managers generally perceived that the primary objective of implementing a quality system was to satisfy their customers. Thus, process-control systems were established under conformity pressures. The indicators used here for measuring process-control systems are the most common requirements in quality management standards (e.g., ISO 9000, QS-9000). The present study indicates that control systems developed in the electronics industry appear to have little value in improving either time-based or cost-related operational performance. As shown in the quality documents we reviewed, most of these control practices have been established for many years without major revisions. Interviews with practitioners revealed that electronics firms sought static rather than dynamic control systems [62]. Unless required by customers or auditors, the firms showed little initiative to make changes in their process control procedures.
Deming [36] believes that a supplier generally has the best and most specialized knowledge of their operational processes, more than their customers. He comments that the use of institutional control systems is a great producer of waste, causing huge wastes whose magnitudes cannot be evaluated or measured. Juran stresses that quality activity includes both "control" and "breakthrough," and "the manager must do both" [62, p. 5]. However, little breakthrough thinking is emphasized in management standards or by customers and, thus, is rarely practiced by the practitioners. As we observed, industrial customers are imposing increasingly strict requirements on the QMS of their suppliers. The quality system of a supplier is audited and assessed prior to the awarding of contracts, and is continuously monitored by the customers. For instance, a big firm recommended that its suppliers to adopt the quality system review (QSR) procedures [51], a standard that is more stringent than ISO 9000.

\section{Routes to Profitability: Revisiting the Classical Theory}

The relationship between quality management, operational performance, and profitability is suggested in the classic literature on quality [28], [35], [38], [44]. Deming's [35] chain reaction suggests that quality improvements lead to cost reductions and, hence, better marketing performance and profit gains (see Fig. 4). The second route of our model (see Fig. 3) provides some empirical support for this argument.

The figures in the empirical model (see Fig. 3) suggest that, compared to cost-related operational efficiency, time-based operational performance has a stronger effect on customer satisfaction. This supports Deming's [36] assertion. Deming [36] states that in a highly competitive business environment, competitive prices are sometimes offered by several firms. In such circumstances, flexibility, lead-time and delivery terms become the emerging criteria [7], [36], [65]. Our interviews suggested that participants in this research saw that prices in the electronics industry had always been under downward pressures due to cut-throat competition [26], [27], [86]. Previous studies [26] report that the average annual decline in prices for purchased parts is approximately $10 \%$ per year and that the steepness of this curve is unique to the electronics industry. Finally, our model shows that the third route leading to customer satisfaction and market growth is the establishment of quality control systems.

These findings may be substantiated by some distinctive features of the electronics industry. Operating in a highly competitive environment and shaped by market pressures, electronics firms must be highly customer oriented and excel themselves in responding to the many guidelines, standards, or requirements set by their customers. Control procedures for the suppliers of electronics products have become increasingly strict. Nevertheless, the dynamic nature of the industry makes some "optimized procedures" readily outdated, making process control fractious and not leading to efficiency. The local electronics 
industry is highly export-oriented with major customers from overseas. The long distance and cultural differences hinder the forging of intimate relationships and make long-term cooperation difficult. Unlike having a supplier next door, customers located far away have no specialized knowledge of the operations of their suppliers and offer no customized advice and technical assistance.

The limitations of this paper can be viewed in terms of the methodology and scope. Methodologically, the data collected here are based on self-reported questionnaires. Although in-depth interviews and industrial visits were carried out to verify the data, individual bias in reporting still existed. In addition, the present study is based on cross-sectional survey research, which provides limited longitudinal evidence on exactly how each quality management construct affects operational performance. In terms of the scope of the study, this research is limited to the study of the electronics manufacturing industry in Hong Kong. Nevertheless, by including a considerable number of internationally based corporations in our study, we have enhanced the generalizability of our findings. For further study, we suggest that similar research should be conducted in different manufacturing industries for comparison.

\section{E. Management Implications}

Several concerns which bear important management implications may be raised. Our study indicates that customer orientation seems to be practiced at a rather superficial level. Operational efforts may be directed to some short-term and immediately assessable targets, instead of to cost efficiency, which requires close and long-term cooperation with customers. Institutional operational control systems are increasingly emphasized by industrial customers. This type of system is developed under customer pressures and relies heavily on quality audits and inspections, discouraging decisive action to achieve higher levels of operational performance. The dynamic nature of quality management and organizational environment is perhaps changing the relationship among quality, operational efficiency, and customer satisfaction. Customers seem to be satisfied with formal quality systems, continuous cost reductions are an industrial norm and time-based efficiency has become the major criterion of performance in a competitive and fast-changing marketplace. This type of change represents the existence of a significant gap between the theory and practice of quality management, highlighting the necessity for a shift in direction that deserves careful attention from both academics and practitioners.

Our findings indicate that instead of requiring quality certification or formal control systems, and relying on supplier quality audits, overseas electronics customers should develop long-term and close relationships with their OEMs or ODMs in this region. This standpoint is also supported by a large number of empirical studies in recent years [68], [81], [83], [84], [90], [91], which have consistently suggested that quality certification is not related to operational performance.

\section{CONCLUSION}

The results in this research support some basic assertions in the literature on quality management. Our results indicate that customer orientation improves operational performance, in particular time-based efficiency and, thus, enhances customer satisfaction. However, it does not directly lead to customer satisfaction. Continuous process improvement enhances cost-related efficiency, supporting the ideas of Deming [35] and Taguchi et al. [89], who stated that the continuous reduction of variations and deviations from target points is the way to decrease operational costs.

On the other hand, we identified some conspicuous deviations of practice from theory. These differences are probably due to the over-generalization of ideas about quality in actual practice. In a competitive and fast-changing operating environment, customer orientation practices are directed to short-term and immediately assessable targets, hindering long-term cooperation. Process-control systems may be developed mainly to satisfy customer requirements, rather than to fulfill operational needs. Accordingly, it seems that a redirection of several quality management practices is necessary.

\section{ACKNOWLEDGMENT}

The authors would like to thank a large number of industrial practitioners for the valuable information they have offered; their enthusiasm in participating in and supporting this study is highly appreciated. The authors are also thankful for the constructive comments of three anonymous referees on an earlier version of this paper.

\section{REFERENCES}

[1] S. L. Ahire and P. Dreyfus, "The impact of design management and process management on quality: An empirical investigation," J. Oper. Manage., vol. 18, pp. 549-575, 2000.

[2] S. L. Ahire, D. Y. Golhar, and M. A. Waller, "Development and validation of TQM implementation constructs," Decision Sci., vol. 27, no. 1, pp. 23-56, 1996.

[3] J. C. Anderson and D. W. Gerbing, "Structural equation modeling in practice: A review and recommended two step approach," Psych. Bull., vol. 103 , pp. 411-423, 1988

[4] J. C. Anderson, M. Rungtusanatham, and R. G. Schroeder, "A theory of quality management underlying the Deming management method," Acad. Manage. Rev., vol. 19, no. 3, pp. 472-509, 1994.

[5] J. C. Anderson, M. Rungtusanatham, R. G. Schroeder, and S. Devaraj, "Path analytic model of a theory of quality management underlying the Deming management method: Preliminary empirical findings," Decision Sci., vol. 26, no. 5, pp. 637-658, 1995.

[6] J. L. Arbuckle, AMOS Users' Guide, 3.6 ed. Chicago, IL: SmallWaters, 1997.

[7] P. Baily, D. Farmer, D. Jessop, and D. Jones, Purchasing Principles and Management, 8th ed. London, U.K.: Pitman, 1998, Financial Times.

[8] T. M. Barker, "Quality engineering by design: Taguchi's philosophy," Qual. Prog., vol. 19, no. 12, pp. 32-42, 1986.

[9] H. Baumgartner and C. Homburg, "Application of structural equation modeling in marketing and consumer research: A review," Int. J. Res. Market., vol. 13, pp. 139-161, 1996.

[10] K. Beasley, Total Quality Management in the Electronics Industry: A User's and Supplier's Guide, Hertfordshire, U.K.: Technical Communications, 1992.

[11] P. M. Bentler and C. Chou, "Practical issues in structural modeling," Sociol. Meth. Res., vol. 16, pp. 78-117, 1987.

[12] B. Bergman and B. Klefsjo, Quality from Customer Needs to Customer Satisfaction. New York: McGraw-Hill, 1994.

[13] G. Binney, Making Quality Work, Lessons from Europe's Leading Companies. London, U.K.: Ashridge, 1992.

[14] S. A. Black and L. J. Porter, "Identification of the critical factors of TQM," Decision Sci., vol. 27, no. 1, pp. 1-21, 1996

[15] G. Bounds, L. Yorks, M. Adams, and G. Ranney, Beyond the Total Quality Management toward the Emerging Paradigm. New York: McGraw-Hill, 1994. 
[16] J. L. Bossert, Supplier Management Handbook. Milwaukee, WI: ASQ Quality, 1994.

[17] M. T. Brannick, "Critical comments on applying covariance structure modeling," J. Org. Behav., vol. 16, pp. 201-213, 1995.

[18] L. R. Burns and D. R. Wholey, "Adoption and abandonment of matrix management programs: Effects of organizational characteristics and inter-organizational networks," Acad. Manage. J., vol. 36, pp. 106-138, 1993.

[19] C. W. Burrill and J. Ledolter, Achieving Quality through Continual Improvement. New York: Wiley, 1999.

[20] P. Y. K. Chau, "Reexamining a model for evaluating information center success using a structural equation modeling approach," Decision Sci., vol. 28, no. 2, pp. 309-334, 1997.

[21] W. W. Chin, "Issues and opinion on structural equation modeling," MIS Quart., pp. 7-16, Mar. 1998.

[22] W. W. Chin and P. A. Todd, "On the use, usefulness, and ease of use of structural equation modeling in MIS research: A note of caution," MIS Quart., pp. 237-246, Jun. 1995.

[23] T. Y. Choi and K. Eboch, "The TQM paradox: Relations among TQM practices, plant performance, and customer satisfaction," J. Oper. Manage., vol. 17, pp. 59-75, 1998.

[24] T. Y. Choi and M. Rungtusanatham, "Comparison of quality management practices: Across the supply chain and industries," J. Supply Chain Manage., vol. 35, no. 1, pp. 20-27, 1999.

[25] G. A. Churchill, Marketing Research: Methodological Foundations, 4th ed. Chicago, IL: Dryden, 1987.

[26] A. P. Cimento and R. J. Knister, "The high-productivity electronics company," McKinsey Quart., no. 1, pp. 21-32, 1994.

[27] E. J. Correia, "Output quality improves as prices continue to fall," Comput. Reseller News, vol. 12, p. 41, 50, Apr. 1999.

[28] P. B. Crosby, Quality is Free: The Art of Making Quality Certain. New York: New Amer. Library, 1979.

[29] —-, Quality Without Tears: The Art of Hassle-Free Management. New York: McGraw Hill, 1984.

[30] R. Cudeck and M. W. Browne, "Cross-validation of covariance structures," Multivariate Behav. Res., vol. 18, pp. 147-167, 1983.

[31] B. G. Dale, C. L. Cooper, and A. Wilkinson, Managing Quality \& Human Resources, A Guide to Continuous Improvement. Oxford, U.K.: Blackwell, 1997.

[32] B. G. Dale and J. S. Oakland, Quality Improvement through Standards, 2nd ed. Cheltenham, U.K.: Stanley Thornes, 1994.

[33] J. W. Dean and D. E. Bowen, "Management theory and total quality: Improving research and practice through theory building," Acad. Manage. Rev., vol. 19, no. 3, pp. 392-418, 1994.

[34] W. E. Deming, Quality, Productivity and Competitive Position. Cambridge, MA: MIT Center Adv. Eng. Study, 1982.

[35] - Out of the Crisis. Cambridge, MA: MIT Center Adv. Eng. Study, 1986.

[36] — The New Economics for Industry, Government, Education, 2nd ed. Cambridge, MA: MIT Center Adv. Eng. Study, 1994.

[37] J. R. Evans and W. M. Lindsay, The Management and Control of Quality. Minneapolis, MN: West, 1993.

[38] A. V. Feigenbaum, Total Quality Control. New York: McGraw-Hill, 1991.

[39] B. B. Flynn, R. G. Schroeder, and S. S. Sakakibara, "A framework for quality management research and an associated measurement instrument," J. Oper. Manage., vol. 11, pp. 339-366, 1994.

[40] B. B. Flynn, R. G. Schroeder, and S. Sakakibara, "The impact of quality management practices on performance and competitive advantage," $D e$ cision Sci., vol. 26, no. 5, pp. 659-691, 1995.

[41] C. Fornell and D. F. Larcker, "Evaluating structural equation models with unobservable variables and measurement error," J. Market. Res., vol. 18 , no. 1 , pp. $39-50,1981$.

[42] C. Forza and R. Filippini, "TQM impact on quality conformance and customer satisfaction: A causal model," Int. J. Prod. Econ., vol. 55, no. 1, pp. 1-20, 1998.

[43] J. Fox, Quality through Design: The Key to Successful Product Delivery. New York: McGraw-Hill, 1993.

[44] D. A. Garvin, Managing Quality: The Strategic and Competitive Edge. New York: Free Press, 1988

[45] D. W. Gerbing and J. C. Anderson, "The effects of sampling error and model characteristics on parameter estimation for maximum likelihood confirmatory factors analysis," Multivariate Behav. Res., vol. 20, pp. 255-271, 1985.

[46] _ "An updated paradigm for scale development incorporating unidemensionality and its assessment," J. Market. Res., vol. 25, no. 5, pp. $186-192,1988$
[47] S. Gilbert, "Business improvement philosophies and techniques, what makes them successful and sustainable?," Asian Pacific J. Qual. Manage., vol. 4, no. 2, pp. 35-43, 1995.

[48] B. Gunter, "A perspective of Taguchi method," Qual. Prog., vol. 20, no. 6, pp. $44-52,1987$

[49] J. F. Hair, R. E. Anderson, R. L. Tatham, and W. C. Black, Multivariate Data Analysis with Readings, 4th ed. Englewood Cliffs, NJ: PrenticeHall, 1995.

[50] M. M. Harries and J. Schaubroeck, "Confirmatory modeling in organizational behavior/human resource management: Issues and applications," J. Manage., vol. 16, no. 2, pp. 337-360, 1990.

[51] D. Harrold, "Designing for six sigma capability," Contr. Eng., vol. 46, no. 1, pp. 62-70, 1999.

[52] R. L. Hensley, "A review of operations management studies using scale development techniques," J. Oper. Manage., vol. 17, pp. 343-358, 1999.

[53] Hong Kong Productivity Council, 1998/99 Techno-Economic and Market Research Study on Hong Kong's Electronics Industry, Hong Kong: Hong Kong Ind. Dept., 1999.

[54] Hong Kong Industry Department, Hong Kong Manufacturing Industry, Hong Kong: Hong Kong Ind. Dept., 1996.

[55] M. A. Hughes, R. L. Price, and D. W. Marrs, "Linking theory construction and theory testing: Models with multiple indicators of latent variables," Acad. Manage. Rev., vol. 11, no. 1, pp. 128-144, 1986

[56] R. E. Hurley and J. M. Laitamaki, "Total quality research, integrating markets and the organization," Calif. Manage. Rev., vol. 38, no. 1, pp. $59-78,1995$.

[57] International Organization for Standardization, ISO 9001: Quality Systems - Model for Quality Assurance in Design, Development, Production, Installation and Servicing. Geneva, Switzerland: ISO, 1994.

[58] R. Jones, G. Arndt, and R. Kustin, "ISO 9000 among Australian companies: Impact of time and reasons for seeking certification on perceptions of benefits received," Int. J. Qual. Reliab. Manage., vol. 14, no. 7, pp. 650-660, 1997

[59] J. M. Juran, Juran on Planning for Quality. New York: Free Press, 1988.

[60] - Juran on Quality by Design, The New Steps for Planning Quality into Goods and Services. New York: Free Press, 1992.

[61] J. M. Juran and F. M. Gryna, Quality Planning and Analysis, 3rd ed. New York: McGraw-Hill, 1993.

[62] J. M. Juran and J. M., Managerial Breakthrough: The Classic Book on Improving Manage. Performance, 2nd ed. New York: McGraw-Hill, 1995

[63] E. K. Kelloway, Using LISREL for Structural Equation Modeling, A Researcher's Guide. Newbury Park, CA: Sage, 1998.

[64] K. Y. Kim, J. G. Miller, and J. Heineke, "Mastering the quality staircase, step by step," Bus. Horiz., pp. 17-21, Jan.-Feb. 1997.

[65] G. Labianca, "Contract manufacturing: Fast growth, low margins," Electron. Bus., vol. 16, no. 18, pp. 97-106, 1990.

[66] C. W. LaHay and J. S. Noble, "A framework for business system and quality management integration," Int. J. Qual. Reliabil. Manage., vol. 15 , no. 6, pp. 566-581, 1998.

[67] C. A. Lengnick-Hall, "Customer contributions to quality: A different view of the customer-oriented firm," Acad. Manage. Rev., vol. 21, no. 3, pp. 791-824, 1996.

[68] M. A. M. Lima, M. Resende, and L. Hasenclever, "Quality certification and performance of Brazilian firms: An empirical study," Int. J. Prod. Econ., vol. 66, pp. 143-147, 2000.

[69] R. M. MacCallum, "Specification searches in covariance structure modeling," Psych. Bull., vol. 100, pp. 107-120, 1986.

[70] R. O. Mueller, Basic Principles of Structural Equation Modeling, A Introduction to LISREL and EQS. Berlin, Germany: Springer-Verlag, 1996.

[71] Nat. Inst. Standards and Technology, 1999 Criteria for Performance Excellence - Malcolm Baldrige National Quality Award Criteria. Gaithersburg, MD: Nat. Inst. Stand. Technol./Amer. Soc. Quality Control, 1999.

[72] S. W. O'Leary-Kelly and R. J. Vokurka, "The empirical assessment of construct validity," J. Oper. Manage., vol. 16, pp. 387-405, 1998.

[73] J. S. Oakland, Total Quality Management. Oxford, U.K.: Heinemann, 1989.

[74] S. Pugh, Total Design, Integrated Methods for Successful Product Engineering. Reading, MA: Addison-Wesley, 1991.

[75] W. Ray, "Why aren't quality programs boosting industry profits?," Electron. Bus., vol. 16, no. 5, pp. 38-39, 1990.

[76] R. Reed, D. J. Lemak, and J. C. Montgomery, "Beyond process: TQM content and firm performance," Acad. Manage. Rev., vol. 21, no. 1, pp. 173-202, 1996 
[77] J. E. Ross, Total Quality Management, Text, Cases and Readings, 2nd ed. Delray Beach, FL: St. Lucie, 1995.

[78] M. Rungtusanatham, C. Forza, R. Filippini, and J. C. Anderson, "A replication study of quality management underlying the Deming management method: Insights from an Italian context," J. Oper. Manage., vol. 17, pp. 77-95, 1998.

[79] W. H. Schmidt and J. P. Finnigan, The Race Without a Finish Line. San Francisco: Jossey-Bass, 1992.

[80] R. E. Schumacker and R. G. Lomax, A Beginner's Guide to Structural Equation Modeling. Mahwah, NJ: Lawrence Erlbaum, 1996.

[81] S. Rahman, "A comparative study of TQM practice and organizational performance of SME's with and without ISO 9000 certification," Int. J. Oual. Reliabil. Manage., vol. 18, no. 1, pp. 35-49, 2001.

[82] E. S. M. Silvia and R. C. MacCallum, "Some factors affecting the success of specification searches in covariance structure modeling," Multivariate Behav. Res., vol. 23, pp. 297-326, 1988.

[83] B. L. Simmons and M. A. White, "The relationship between ISO 9000 and business performance: Does registration really matter?," J. Managerial Issues, vol. 11, no. 3, pp. 330-343, 1999.

[84] J. Singels, G. Ruel, and H. Water, "ISO 9000 series: Certification and performance," Int. J. Qual. Reliabil. Manage., vol. 18, no. 1, pp. 62-75, 2001

[85] H. Shin, D. Collier, and D. Wilson, "Supply management orientation and supplier/buyer performance," J. Oper. Manage., vol. 18, no. 3, pp. 317-333, 2000.

[86] G. Stout, "Continuous quality improvement in the electronics industry," Qual., pp. 16-22, Feb. 1993.

[87] G. Taguchi, Taguchi on Robust Technology Development, Bringing Ouality Engineering Upstream. New York: ASME Press, 1993.

[88] G. Taguchi and D. Clausing, "Robust quality," Harv. Bus. Rev., vol. 63, Jan.-Feb. 1990.

[89] G. Taguchi, E. A. Elsayed, and T. Hsiang, Quality Engineering in Production Systems. New York: McGraw-Hill, 1989.

[90] M. Terziovski, D. Samson, and D. Dow, "The impact of ISO 9000 certification on customer satisfaction," Asia Pacific J. Qual. Manage., vol 4, no. 2, pp. 66-68, 1995

[91] _ , "The business value of quality management systems certification: Evidence from Australia and New Zealand," J. Oper. Manage., vol. 15, pp. 1-18, 1997.

[92] M. Treacy and F. Wierema, "Customer intimacy and other value disciplines," Harv. Bus. Rev., vol. 71, no. 1, pp. 84-93, 1993.

[93] J. D. Westphal, R. Gulati, and S. M. Shortell, "Customization or conformity? An institutional and network perspective on the content and consequences of TQM adoption," Admin. Sci. Quart., vol. 42, pp. 366-394, 1997.

[94] H. G. Willett, "What drives quality at Intel," Electron. Bus., vol. 17, no. 19, pp. 28-40, 1991.

[95] C. L. Yeung, "Quality management system and its association with organizational performance," Ph.D. dissertation, The University of Hong Kong, Kowloon, Hong Kong, 1999.
[96] C. L. Yeung and L. Y. Chan, "Quality management system development: Some implications from case studies," Comput. Ind. Eng., vol. 35, no. 1-2, pp. 221-224, 1998.

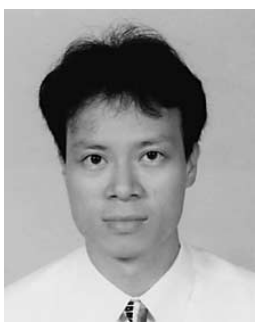

Andy C. L. Yeung received the M.S. degree from the University of Bradford, Bradford, U.K., and the $\mathrm{Ph} . \mathrm{D}$. degree from the University of Hong Kong.

$\mathrm{He}$ is currently an Assistant Professor with the Department of Logistics, Hong Kong Polytechnic University. His research interests include operations management, supply chain management, and general management. He has published papers in Journal of Operations Management and International Journal of Production Research.

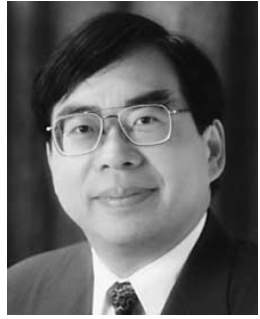

T. C. Edwin Cheng received the B.S. degree from the University of Hong Kong, the M.S. degree from the University of Birmingham, Birmingham, U.K., and the Ph.D. degree from the University of Cambridge, Cambridge, U.K.

He is currently a Chair Professor of Managemen with the Department of Logistics, The Hong Kong Polytechnic University. His research interests include operations management and operations research. $\mathrm{He}$ has published over 200 journal papers and coauthored two books.

Dr. Cheng received the Outstanding Young Engineer of the Year Award of the IIE in 1992, and the Croucher Foundation Senior Research Fellowship in 2001 He was named one of the "most cited scientists" in engineering over the period 1992-2002 by the ISI Web of Knowledge in 2002.

Ling-Yau Chan received the M.Phil. degree in mathematics and the Ph.D. degree in statistics from The University of Hong Kong, Kowloon, in 1978 and 1987, respectively.

He joined the Teaching Staff of the Department of Industrial and Manufacturing Systems Engineering, The University of Hong Kong, in 1984, and is now an Associate Professor and the Head of the Department. His research interests include statistical process control, design of experiments, optimal design, reliability analysis, logistics, and supply chain management.

Dr. Chan is a Fellow of the Royal Statistical Society and a member of the Chartered Institute of Logistics and Transport. 